\title{
The necessity of implementing telemedicine systems in the Islamic Republic of Iran
}

Sareh Keshvardoost, ${ }^{1}$ Reza Dehnavieh ${ }^{2}$ and Kambiz Bahaadinibeigy ${ }^{3}$

${ }^{1}$ Medical Informatics Research Center, Institute for Future Studies in Health, Kerman University of Medical Sciences, Kerman, Islamic Republic of Iran. ${ }^{2}$ Health Foresight and Innovation Research Center, Institute for Futures Studies in Health, Kerman University of Medical Sciences, Kerman, Islamic Republic of Iran. ${ }^{3}$ Modelling in Health Research Center, Institute for Future Studies in Health, Kerman University of Medical Sciences, Kerman, Islamic Republic of Iran. (Correspondence to: Kambiz Bahaadinibeigy: Kambizb321@gmail.com; Kbahaadini@kmu.ac.ir).

Citation: Keshvardoost S; Dehnavieh R; Bahaadinibeigy K. The necessity of implementing telemedicine systems in the Islamic Republic of Iran. East Mediterr Health J. 2021;27(2):113-115 https://doi.org/10.26719/emhj.21.001

Received: 05/04/20; accepted 20/07/20

Copyright (c) World Health Organization (WHO) 2021. Open Access. Some rights reserved. This work is available under the CC BY-NC-SA 3.o IGO license (https://creativecommons.org/licenses/by-nc-sa/3.o/igo)

\section{Introduction}

Telemedicine refers to the provision of health-care services using information and communications technology when place or time creates distance between the provider and the receiver of the services (1). The most significant benefit of telemedicine is its potential for providing equal health services through meeting the demands of patients, from any place, and at any time. Today, telemedicine has gradually becomes a fundamental component of health-care systems, in such a way that the United States Department of Health and Human Services has reported that more than $60 \%$ of health-care institutions and 40 to $50 \%$ of hospitals in the United States of America use telehealth (2).

Despite the growth of this method of delivery of health care in high-income countries, it has not been included in the routine provision of health-care service in the Islamic Republic of Iran. Analyzing incentives is always beneficial for a better understanding of necessity of implementation a system. Hence, a focus group session was held and asked the opinion of two experts [one telemedicine expert $(\mathrm{KB})$ and a health future studies expert (RD)]. We also considered useful literature for this purpose. This can provide the executive managers and policy-makers with an objective view of the current situation and the necessity of implementing telemedicine in the future.

\section{The aging population and chronic diseases}

The Islamic Republic of Iran is a middle-income country and population aging has an upward trend in the country. It is predicted that $33 \%$ of the population will be aged over 60 years by 2050 (3). The probability of developing age-related chronic diseases such as cardiovascular illnesses, diabetes, Alzheimer's disease, and chronic respiratory diseases are increasing, since about $80 \%$ of older people have at least one chronic illness (4). According to the World Health Organization (WHO) report in 2018, chronic noncommunicable diseases accounted for $67 \%$ of causes of deaths in the Islamic Republic of Iran (cardiovascular diseases $43 \%$, cancers $16 \%$, diabetes $4 \%$, chronic respiratory diseases 4\%) (5). Moreover, the disability caused by these diseases in the country is more significant compared with the global average (6). This imposes serious economic problems on the health system through reduction in the quality of the patient's life, decreasing workforce efficiency, and using more medical resources due to increased visits, frequent hospitalizations, prolonged length of stay, and greater medication consumption.

For example, Esteghamati et al. showed that more than half of the direct expenses of treating diabetic patients $(53 \%)$ were related to complications of diabetes (7); delay in diagnosis and unequal access to health-care services are contributing factors to the progression of disease complications and increased medical expenses. In another study aiming to estimate the economic burden resulting from cardiovascular disease in the southwest of the Islamic Republic of Iran, hospital expenses (visit, diagnosis, surgical procedures, and nursing) formed more than $60 \%$ of direct medical expenses, while transportation and traveling expenses formed more than $40 \%$ of direct nonmedical expenses (8). Therefore, a major portion of health expenses is related to hospital care of these patients. In many high-income countries, in order to reduce these expenses home-care telemedicine is provided for older people and patients with chronic conditions.

In this regard, a randomized controlled trial aiming to assess the effect of home telemonitoring systems on health, quality of life, and annual expenses of patients with diabetic and COPD, had revealed that during the utilization of this system, hospitalization expenses decreased, which compensated for the expense of implementing telemedicine. This study showed that telemonitoring had led to a higher quality of life for patients in the intervention groups while preserving the quality of services (9).

\section{Unbalanced geographical distribution and the number of physicians}

Another challenge facing the health system is the number and unequal distribution of specialists. When there is no access to an adequate number of doctors, we would face a decrease in the quality of care and an increase in medical errors. Physicians per capita (general, specialist) 
in the Islamic Republic of Iran is 1.6 for every 1000 people, while in high-income countries such as Australia and Germany, this index is 3.7 and 4.2, respectively. Moreover, among the countries of Region, the Islamic Republic of Iran stands after countries such as Kuwait, Oman, Qatar, Saudi Arabia and Turkey (10). In remote areas where the workload is high, physicians are noted to be reluctant to work in those places. Results of a study conducted in the country showed the geographical distribution of physicians was heterogeneous, with the highest number of specialist physicians (about 35\%) working in Tehran province (11). However, in some domains the number of specialists is disproportionate with demand. Also, the distribution of diseases and deaths varies in different provinces and the number of specialists is not balanced with the health-care needs of those areas. Moreover, there is a shortage of specialists in some specialties such as neurology, orthopaedics, radiology, otolaryngology and oph

\section{Size and population}

In terms of global size and population, the Islamic Republic of Iran ranks 18th and 17th respectively (12). The scattered population and geographical vastness of the country are some of the main factors and incentives for implementing telemedicine.

\section{Road accidents}

In the Islamic Republic of Iran road and metropolitan accidents cause a significant number of deaths in people aged under 45 years, and the second cause of mortality and morbidity after cardiovascular diseases (13). Injuries resulting from traffic accidents cause a wide range of expenses such as years of life lost (YLL), years lived with disability and medical and rehabilitation expenses, which impose significant pressure on the Iranian healthcare system. A study conducted by Ainy et al. (2013) demonstrated that financial losses resulting from accidents (death and injury) were equal to $6.64 \%$ of the Gross National Income of the country, which is much higher than the worldwide average(14).

\section{Air pollution}

The number of deaths caused by air pollution 4 times higher than that of AIDS. According to a World Bank report, more than 21000 people died from air pollution in 2013 in the Islamic Republic of Iran (15). Exposure to air pollution leads to the progression of cardiovascular diseases, brain stroke, COPD, lung cancer, and respiratory infections. Besides having devastating effects on health, air pollution also leads to an increase in economic expenses for the country (15).

A time-series study analyzing the effect of air pollution on the Iranian economy showed that a $1 \%$ increase in the carbon dioxide index leads to $3.32 \%$ and $1.16 \%$ increase in public and private health expenses, respectively (16). In this regard, we can mention the environmental benefits of telemedicine, which reduces the traffic and air pollution through preventing unnecessary transportation, especially in areas which are the focal points of healthcare services. For example, in the study by Wootton et al. a telemedicine network that had been established in the northeast of Scotland managed to prevent 2000 patients from travelling in one year, which led to a 59-ton decrease in carbon dioxide production (17).

\section{High probability of natural disasters}

Since 2000 various natural disasters have occurred in the Islamic Republic of Iran, some of which have caused heavy financial loss and casualties. The earthquake that occurred in Bam in 2003 caused 30000 deaths and left more than 22000 people injured and more than 45000 people homeless. The earthquake that occurred in Kermanshah in 2017 caused 620 deaths and left 9400 people injured and more than 115000 people homeless (18). In such conditions, due to the magnitude of the incident, the high number of the injured and impassable roads, it is difficult to provide timely assistance and there are delays accessing health-care services. Delays in treatment may lead to irreparable losses. Using telemedicine, we can provide timely treatment for the injured, reduce the time of treatment, and avoid serious injuries through giving specialized consultation and educating service providers (19).

\section{Epidemic diseases}

The Islamic Republic of Iran was one of the first countries in the Middle East to experience the spread of COVID-19. By 19 June 2020, more than 197000 people had been infected and more than 9000 had died. Official statistics of new confirmed cases revealed a re-ascending trend of the disease (20). COVID-19 will not be the last pandemic, therefore it is necessary to use strategies to control the speed of infection of the virus and manage the situation. There is plenty of evidence that telehealth is effective in the management of various epidemics such as the SARS outbreak in Taiwan and Ebola in Africa. Today, many countries are using telehealth in the fight against COVID-19, allowing chronically ill patients who are at a higher risk of developing severe symptoms of COVID-19 to access medical staff for periodic examinations (21).

\section{Conclusion}

Based on current trends the use of telemedicine in the Islamic Republic of Iran is inevitable and requires planning to strengthen its infrastructure, including full cooperation and policy-making among health-care organizations, the Ministry of Communications and Information, insurance companies, and banks. Globally, many governments are upgrading services that will lend themselves to effective telemedicine. For example, the Australian government invested substantially to expand its IT infrastructure and national broadband network to allow Australians access to high-speed internet services (22). In addition, India has had a slow but positive steady rise in the adoption of this technology in its health-care service (23). Therefore, applying the successful experiences of other countries in overcoming barriers can contribute significantly to improving the health sector in the Islamic Republic of Iran. 


\section{References}

1. World Health Organization. Telemedicine: opportunities and developments in member states. Report on the second global survey on eHealth. Geneva: World Health Organization; 2010.

2. US Department of Health and Human Services. Report to Congress: E-health and telemedicine. Washington, DC: Department of Health and Human Services; 2016 (https://aspe.hhs.gov/system/files/pdf/206751/TelemedicineE-HealthReport.pdf).

3. World Health Organization. World report on ageing and health. Geneva: World Health Organization; 2015.

4. Fontana L. Modulating human aging and age-associated diseases. Biochimica et Biophysica Acta (BBA)-General Subjects. 2009;1790(10):1133-8.

5. World Health Organization. Noncommunicable diseases (NCD) Country Profiles 2018. Geneva: World Health Organization; 2018 (https://www.who.int/nmh/countries/irn_en.pdf?ua=1).

6. Emamgholipour S. The burden of elderly's non-communicable diseases in Iran. Evidence based health policy, management and economics. 2017;1(3):128-30.

7. Esteghamati A, Khalilzadeh O, Anvari M, Meysamie A, Abbasi M, Forouzanfar M, et al. The economic costs of diabetes: a population-based study in Tehran, Iran. Diabetologia. 2009;52(8):1520-7.

8. Emamgholipour S, Sari AA, Pakdaman M, Geravandi S. Economic Burden of Cardiovascular Disease in the Southwest of Iran. International Cardiovascular Research Journal. 2018;12(1).

9. Bohingamu Mudiyanselage S, Stevens J, Watts JJ, Toscano J, Kotowicz MA, Steinfort CL, et al. Personalised telehealth intervention for chronic disease management: A pilot randomised controlled trial. Journal of telemedicine and telecare. 2019;25(6):343-52.

10. The World Bank. Physicians (per 1,00o people). Washington, DC: The World Bank; 2014 (https://data.worldbank.org/indicator/ SH.MED.PHYS.ZS?end=2014\&start=1960\&view=chart).

11. Noori Hekmat S, Hashemi H, Haghdoost A, Haji Aghajani M, Janbabaee G, Maher A, et al. Specialized and geographic distribution of specialists in Iran in 2016 and its estimates in 2026. Iran J Epidemiol. 2018;13:122-32.

12. World Population Review. Population of cities in Iran (2020). (http://worldpopulationreview.com/countries/iran-population/ cities/).

13. Saadat S, Yousefifard M, Asady H, Jafari AM, Fayaz M, Hosseini M. The most important causes of death in Iranian population; a retrospective cohort study. Emergency. 2015;3(1):16.

14. Ainy E, Soori H, Ganjali M, Le H, Baghfalaki T. Estimating cost of road traffic injuries in Iran using willingness to pay (WTP) method. PLoS one. 2014;9(12):e112721.

15. The World Bank. The cost of air pollution: strengthening the economic case for action. Washington, DC: The World Bank; 2016.

16. Raeissi P, Harati-Khalilabad T, Rezapour A, Hashemi SY, Mousavi A, Khodabakhshzadeh S. Effects of air pollution on public and private health expenditures in Iran: A time series study (1972-2014). Journal of Preventive Medicine and Public Health. 2018;51(3):140.

17. Wootton R, Tait A, Croft A. Environmental aspects of health care in the Grampian NHS region and the place of telehealth. Journal of telemedicine and telecare. 2010;16(4):215-20.

18. Saberian P, Kolivand P-H, Hasani-Sharamin P, Dadashi F, Farhoud D. Iranian emergency medical service response in disaster; report of three earthquakes. Advanced Journal of Emergency Medicine. 2019;3(2).

19. Ajami S, Lamoochi P. Use of telemedicine in disaster and remote places. Journal of Education and Health Promotion. 2014;3.

20. Worldometers. COVID-19 Coronavirus Pandemic (https://www.worldometers.info/coronavirus/country/iran/).

21. Keshvardoost S, Bahaadinbeigy K, Fatehi F. Role of telehealth in the management of COVID-19: lessons learned from previous SARS, MERS, and Ebola outbreaks. Telemedicine and e-Health. 2020 Apr 23.

22. Australian Digital Health Agency. Australia's National Digital Health Strategy; Canberra: Australian Digital Health Agency; 2017.

23. Chellaiyan VG, Nirupama AY, Taneja N. Telemedicine in India: Where do we stand?. Journal of Family Medicine and Primary Care. 2019 Jun;8(6):1872. 